Supplement of Biogeosciences, 16, 1657-1671, 2019

https://doi.org/10.5194/bg-16-1657-2019-supplement

(C) Author(s) 2019. This work is distributed under

the Creative Commons Attribution 4.0 License.

(c) (1)

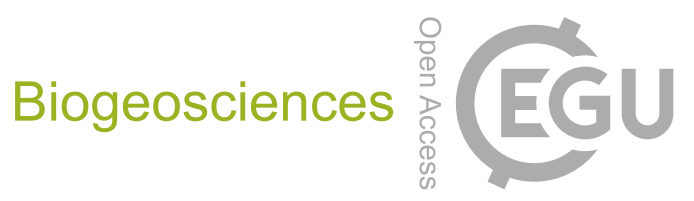

Supplement of

\title{
Reviews and syntheses: Dams, water quality and tropical reservoir stratification
}

\section{Robert Scott Winton et al.}

Correspondence to: Robert Scott Winton (robert.winton@usys.ethz.ch)

The copyright of individual parts of the supplement might differ from the CC BY 4.0 License. 


\section{Methods}

\subsection{Literature review}

For a topic as broadly discipline-spanning and well-covered as the relationship between dams and the environment, a systematic comprehensive literature review is not feasible. Instead we started with a review of the 50 most-cited papers

5 matching the search terms of "water quality" AND "dam" OR "reservoir." From here we extended our review to papers cited by or cited within these influential papers and followed up with specific searches for low latitude case-studies of important emergent sub-topics, such as habitat loss due to sediment trapping, oligotrophication, altered thermal regimes and hypoxia.

\subsection{Uncertain mixing behavior of some Brazilian reservoirs}

Padisak et al (2000) cites a descriptive paper (Tundisi, 1990), which argues that because of the low residence time and high

10 discharge of many Brazilian reservoirs that most reservoirs in the state of Sao Paulo should be polymictic, with only short stratification periods of a few hours. A counterexample to this assertion comes from a study that found a Sao Paulo reservoir, Capivara, to be monomictic with a strongly stratified summer season (Naliato et al., 2009). Another compelling counterexample is the Tucurui reservoir, which although located outside the state of Sao Paulo, has similar residence time and mean depth to the reservoirs Tundisi (1990) and Padisak et al (2000) suggest do not stratify. Tucurui has a 4-month stratification

15 period coinciding with the dry season during which bottom waters become anoxic (Deus et al., 2013). The polymictic status of Tres Irmaos and Ilha Solteira appears to be based on morphologic and hydrologic concepts rather than any empirical observations, such as seasonal depth profiles. There may be some indirect evidence based on temporal patterns of phytoplankton community composition, but the classification appears to have mostly been given as a generalization of the region's many reservoirs and not a specific prescription for these two bodies (Padisák et al., 2000; Tundisi, 1990). Given that

20 other Brazilian reservoirs with similar physical characteristics are known to exhibit strong seasonal stratification, we prefer to opt to report the stratification behavior of these reservoirs as "possible," despite Padisak et al's (2000) suggestion that they are likely to be polymictic. Further field research will likely be required to resolve this ambiguity.

\subsection{Densimetric Froude Number and stratification analysis}

25 From our review of literature, it became clear that the process of thermal and/or chemical stratification of reservoirs is a major driver of changes in water quality. In order to assess the prevalence of stratification-related water quality changes, we review literature on the factors driving the physical processes of stratification and mixing, with a focus on the behavior of tropical and sub-tropical lakes and reservoirs and the conclusions of pervious analyses. Since there is some ambiguity in the literature, we follow up with our own analysis of low latitude reservoir stratification behavior. For this analysis, we extracted morphometric 30 information on the all reservoirs located between $\pm 35^{\circ}$ latitude with volume greater $10 \mathrm{~km}^{3}$ from the International Commission 
on Large Dams (ICOLD) World Register of Dams database. For each of these 54 reservoirs we searched (using Google Scholar) for published information on stratification behavior by entering the terms [reservoir name] AND "stratification," and [reservoir name] AND "thermocline." Based on these searches, we classified reservoirs as either having extended periods of (at least seasonal) stratification or not. Reservoirs for which we were unable to determine mixing or stratification behavior we

5 classified as "unknown," though it is possible that some information on these reservoirs may exist in inaccessible gray literature that our searches missed. We classified as "possibly stratifying" two reservoirs for which authors suggested that they might be polymitic based on regional generalizations, but for which we could not find any empirical evidence. For each of the 54 reservoirs we also estimated the tendency to stratify by calculating a Densimetric Froude Number (F), which compares the inertial force, based on mean flow-through velocity with the gravitational force tending to maintain densimetric stability (Orlob

10 1983, Deas 2000). We use a simplified formula using length (L), depth (D), discharge (Q) and volume (V): F = 320(L/D) (Q/V) (Parker, Benedict \& Tsai, 1975). For F values greater than 1, stratification is unlikely; for F values much less than 1, reservoirs should be strongly stratified; F values between 0.1 and 1 indicate weak stratification (Orlob 1983, Ledec and Quintero 2003). Depth and Volume data are from the ICOLD database. For Q, we used mean annual discharge values from the Global Runoff Data Centre (www.bafg.de/GRDC/EN), which provides a global data set of gauging stations. We estimated reservoir length 15 using the ruler tool on Google Earth, measuring the distance from each dam wall to the most distal end of the furthest reservoir arm. We assess the stratification behaviour of this set of 54 low latitude reservoirs using Froude, literature review and comparing morphometric properties to an lake classification systems proposed by Hutchinson and Loffler (1956) and Lewis (2000). 